\title{
Awareness of Alcohol Advertisements and Perceived Influence on Alcohol Consumption: A Qualitative Study of Nigerian University Students
}

\section{Authors: Emeka W. Dumbili and Clare Williams}

\section{Journal: Addiction Research \& Theory}

\begin{abstract}
Despite the growing alcohol marketing activities of the transnational alcohol industries in Nigeria, little research has focused on their effects on Nigerian youths. This study explores students' awareness of electronic and outdoor alcohol advertisement on campus and around students' off-campus residential and leisure sites, and the extent to which they perceive it to affect their drinking. Thirty-one in-depth interviews were conducted with male and female undergraduate students (aged 19-23 years) from a south-eastern Nigerian university. Alcohol advertisements on television, posters, billboards and the branded fences of bars are common on campus and around students' off-campus residential and leisure spaces. While students were exposed to television alcohol advertisements aired during football games, movies and news hours, they regularly saw point-of-sale and other outdoor advertisements on and around the campus. Students demonstrated sophisticated levels of awareness of alcohol advertisements, to the extent that they 'identified' brand names, vividly described the advertising messages they had seen and named specific bars, restaurants and other sites where they had seen alcohol advertisements regularly. While
\end{abstract}


alcohol advertisement influenced men to consume new products, it also affected their brand preference on a permanent basis. Although alcohol advertisements appear not to have influenced the women, it is argued that this was because they were exposed to the advertisements of alcoholic brands that are categorised as 'men's alcohol' in Nigeria. The results suggest that while effective monitoring of electronic and outdoor advertisements should be reinforced, policymakers may consider replacing self-regulation with evidencebased alcohol control regulatory measures in Nigeria.

Keywords: Alcohol, advertising, marketing, Nigeria, policy; qualitative research

\section{Introduction}

Internationally, alcohol is the most commonly used psychoactive substance among young people, and one of the leading causes of morbidity and mortality among this group (Davoren et al., 2016; Kypri et al., 2009; Stockings et al., 2016). In 2010, alcohol accounted for $5.5 \%$ of the global burden of disease and injury and also caused 4.9 million deaths (Lim et al., 2013). In sub-Saharan Africa, heavy episodic drinking is prevalent and alcohol-related problems are growing (Ferreira-Borges, Rehm, Dias, Babor, \& Parry, 2016). Research shows that in 2012, $6.4 \%$ of the deaths in Africa (224, 000 men; over 80, 000 women) were alcoholrelated, and $4.7 \%$ of people in Africa experienced disability-adjusted life years, due to alcohol consumption (Ferreira-Borges et al., 2016). In the Nigerian context, studies concerning the general population show that among other problems, alcohol consumption 
is a risk factor for cancer (Qian et al., 2014), periodontal disease (Akpata et al., 2014), accidents and injuries (Rehm et al., 2009).

Among Nigerian students, alcohol consumption also constitutes a serious health concern, because drinking games (Dumbili, 2015b) and other hazardous drinking patterns (Abayomi, Onifade, Adelufosi, \& Akinhanmi, 2013) are prevalent. These consumption patterns exacerbate alcohol-induced anxiety (Adewuya, Ola, \& Aloba, 2006), violence, accidents and self-inflicted injuries (Abayomi et al., 2013). Alcohol consumption among Nigerian students also contributes to risky sexual behaviours (Chikere \& Mayowa, 2011; Dumbili, 2016a) and mental health disorders (Igwe \& Ojinnaka, 2010).

Globally, evidence shows that one major factor that facilitates young people's drinking is alcohol marketing (i.e., advertising and promotions (Roberts et al., 2016; Smith \& Foxcroft, 2009; Unger, Schuster, Zogg, Dent, \& Stacy, 2003)). While marketing increases the availability and accessibility of alcohol and the amount that is consumed (Anderson, de Bruijn, Angus, Gordon, \& Hastings, 2009; Babor et al., 2010), it also creates conditions that heighten alcohol-related harms (Pettigrew et al., 2016; Rehm et al., 2009). Despite the above-stated issues and other noticeable alcohol-related harms in Nigeria, alcohol marketing is increasing rapidly, and no effective policies to control alcohol marketing are in place in Nigeria (Ferreira-Borges, Esser, Dias, Babor, \& Parry, 2015).

Again, despite the fact that several studies concerning Western countries have investigated the influence of alcohol advertising on young people's drinking, little is known about how alcohol advertising influences young people in sub-Saharan Africa, and even less is known about Nigeria. This study aims to shed light on a culturally specific understanding of young people's awareness of alcohol advertisement and how they respond to it. 
Specifically, the objective of this study is to explore students' awareness of alcohol advertisements and their perceptions of how it influences their drinking behaviours.

\section{Alcohol Advertising and Young People's Drinking Behaviour}

Young people's awareness of, and exposure to alcohol advertisements, affect their drinking behaviours (Anderson et al., 2009; Babor et al., 2010). The results of cross-sectional research (e.g., Austin, Chen, \& Grube, 2006) and reviews of longitudinal studies (Anderson et al., 2009; Smith \& Foxcroft, 2009) have shown that while awareness of, and exposure to alcohol advertisements have synergetic links with alcohol initiations, they also influence the frequency and quantity of alcohol that is consumed by adolescents and young adults. One of the major reasons why awareness of, and exposure to alcohol advertisements influence young people is that advertisements promote positive beliefs about the benefits of alcohol (Anderson et al., 2009). Although the alcohol industry's self-regulatory measures and government policies on alcohol advertising exist, especially in Western countries (Anderson, Chisholm, \& Fuhr, 2009; Jernigan, 2012), young people's exposure to alcohol advertising and its effects on their drinking behaviours are nonetheless evident (Martino et al., 2016).

In Australia, Jones and Magee (2011) found that adolescents were highly exposed to alcohol advertisements in the electronic and print media such as television, newspapers, and billboards. The study also showed that these adolescents were exposed to alcohol advertisements in bars, pubs and bottleshops. While the high exposure to advertisements in bottleshops, bars or pubs resulted in alcohol initiation, it also had an association with regular and increased drinking (Jones \& Magee, 2011). Based on these results, Jones and 
Magee (2011 p.,636) concluded that "exposure to alcohol advertisements across a variety of media is strongly associated with drinking patterns". Another Australian study that examined exposure to alcohol advertising during televised football, cricket and rugby games found that these games attracted $60 \%$ of all the alcohol advertisements in sports (Carr et al., 2015). Carr et al. (2015) also revealed that adolescents' and young adults' exposure to advertisements during these games was high, and $47 \%$ of the exposure was during the day. Qualitative studies conducted in the same country found that sales staff (Pettigrew et al., 2015) and the strategic packaging of 'alcohol energy drinks' (Jones, Barrie, \& Berry, 2012) positively influence young people's alcohol use.

In a study that examined 3415 German adolescents in the sixth and eighth grades, Morgenstern, Isensee, Sargent, and Hanewinkel (2011) revealed that 70\% had seen alcohol advertisements, and exposure to these advertisements had a significant relationship with their current alcohol use and binge drinking. Morgenstern et al. (2011) also reported that exposure to advertisements influenced non-drinkers to develop positive attitudes towards alcohol initiation. In another study that examined young people's exposure to television advertisements in the UK, the Netherlands and Germany, Patil et al. (2014) found that those aged 10-15 years in the UK and those aged 13-19 years in the Netherlands "were significantly more exposed to alcohol advertising than adults" (Patil et al., 2014 p., 563). Additionally, qualitative research in the UK revealed how adolescents were aware of alcohol advertising and promotions, and how alcohol marketing shaped their attitudes toward alcohol brands (Gordon, Moodie, Eadie, \& Hastings, 2010).

Liking or identifying with advertising models influences young people's alcohol use (Austin et al., 2006) because, through the principle of imitation, they copy the drinking 
behaviours of media "characters...as a guide to what are 'normal' drinking practices" (Atkinson, Bellis, \& Sumnall, 2013 p.91-92). In America, Chen et al. (2005) reported that liking specific elements that were portrayed in televised beer advertisements among adolescents encouraged them to endorse the products and also influenced their intent to purchase the brands advertised. Chen et al. (2005 p., 563) argued that males rated beer advertisements as having more influence than their female counterparts, and this was because the advertisements they were exposed to mainly portrayed "masculine themes". In

a similar vein, Roberts et al. (2016) reported that young people's exposure to advertisements had an association with the consumption of the brands they were exposed to their advertisements. This large and growing body of literature has provided strong evidence supporting the fact that advertising influences young people's drinking behaviours. Therefore, reducing their awareness of, and exposure to advertisements may reduce their drinking (Saffer \& Dave, 2006).

\section{Alcohol Marketing in Contemporary Nigeria}

As indicated above, diverse alcohol consumption patterns exist among Nigerian youths, and one factor that appears to influence their drinking is alcohol marketing. Although there is a paucity of empirical studies on the effects of alcohol advertising on Nigerian youths, the available literature (e.g., Obot, 2013; Dumbili, 2016b) indicates that alcohol marketing, especially sales promotions targeting young Nigerians is increasing. Obot and Ibanga (2002) reported that alcohol advertisements portray positive references to alcohol's benefits. Also, de Bruijin, Ferreira-Borges, Engels, and Bhavsar (2014) found that alcohol companies in 
Nigeria use posters, appealing sporting materials and product displays (on the streets) to advertise their brands.

Regarding regulation, there are no written national alcohol control policies in Nigeria (Ferreira-Borges et al., 2015), and the government does not directly regulate the advertising industry (de Bruijin et al., 2014). The “Advertising Practitioners Council of Nigeria" (APCON, an agency that registers practitioners and vets advertising materials (APCON, 2014)) oversees advertising in the country (de Bruijin et al., 2014). APCON's 'Code of Practice' states that "advertisements for alcoholic beverages shall not be aired between 6:00am and 8:00pm on radio and between 6:00am and 10:00pm on television" (Akpotaire, 2016). The code also stipulates that outdoor advertising materials shall not be placed within 200 metres of hospitals, schools, worship areas and sports venues (Akpotaire, 2016; de Bruijin et al., 2014). Evidence shows that one of the strategies of reducing young people's exposure to alcohol advertising is time restrictions, but this has been found to produce mixed results in Western countries (Ross, Bruijn, \& Jernigan, 2013).

Although APCON's regulations exist, they are neither enforced nor obeyed by alcohol companies and marketers. For example, during the 2013 "African Nations Cup" (football competition among African countries), "Guinness Nigeria" breached the code by airing their 'Guinness Stout' advertisements on satellite television channels during the day (Ademigbuji, 2013). The government's economic interest (Obot, 2007) and neo-liberal policies that encourage industry self-regulation have been blamed for the non-enforcement of these regulations (Dumbili, 2014). One of the consequences of this weak regulatory environment is that alcohol advertisements in Nigeria portray features that have been outlawed in countries with stringent policies. For example, some transnational alcohol companies in 
Nigeria embed their advertisements with materials that portray how drinking is associated with success, and how some brands enhance sexual virility and strength (Obot \& Ibanga, 2002). Against this backdrop, this study explores awareness of alcohol advertisements and young people's drinking in Nigeria.

\section{Methods}

This article draws on a wider study that examined three elements: the gendering of alcohol, the role of alcohol marketing in students' drinking behaviours and how media consumption mediates students' alcohol consumption. Works focusing on alcohol consumption and social identity construction (Dumbili, 2015b), how the use of female students to promote beer brands in male-dominated leisure spaces influences men's alcohol consumption (Dumbili, 2015c), and how social events sponsorships create spaces that encourage alcohol consumption (Dumbili, 2016b) have already been published from the data sets. This article focuses on the role of alcohol marketing in students' drinking behaviours. The study was conducted on a university campus located in a city of Anambra State, in south-eastern Nigeria. The Nigerian University and Brunel University Ethics Boards approved the study before the data were collected by the first author (a male) between September and December, 2013.

The participants were recruited from nine university faculties using word-of-mouth and snowballing approaches. On campus, the researcher approached students and introduced the project to them. After establishing rapport, the students were then asked if they drank alcohol. Those who self-identified as current alcohol users were then asked if they would consider participating in the study and sharing their experiences of alcohol use. Those who indicated interest were provided with an information sheet that detailed the 
aims of the study, the role of participants and the potential benefits and disadvantages ${ }^{1}$ of participation, the methods for securing data and maintaining confidentiality, and the voluntary nature of participation. While 26 (20 males and six females) were recruited via this approach, snowballing methods facilitated the recruitment of an additional three females and two males. These techniques became necessary for the successful recruitment of female participants. While alcohol consumption among young people is a sensitive issue in Nigeria and elicits socio-cultural disapproval, young female drinkers are particularly stigmatised (Dumbili, 2015b). Young people, especially females, are not easily accessible for such studies, and reaching them through any means that may expose their identity will hinder their participation. All the names used in the results section are pseudonyms.

\section{Participants, interviews and data analysis}

Thirty-one in-depth interviews lasting 33-90 minutes were conducted with 22 male and nine female undergraduate students, aged 19-23 years. The interviews were recorded with a digital device with the permission of the participants. All but one of the participants was from the $\lg b o^{2}$ ethnic group. This is mainly because of admission policies in Nigeria, in that universities have 'catchment areas' and admission quotas. Thus, gaining admission outside

\footnotetext{
${ }^{1}$ For example, talking about their alcohol intake might potentially upset some participants, in that they could potentially realise that they were drinking to excess.

${ }^{2}$ The Igbo ethnic group is one of the three predominant ethnic groups in Nigeria. They live in the south-east where the data were collected.
} 
one's 'catchment area' or ethnic group is often difficult. All the participants also selfidentified as Christians.

The interviews were transcribed verbatim, and a thematic analysis was undertaken (by the first author) to identify patterns of meaning in the data set (Braun \& Clarke, 2006). Following Silverman (2011), a preliminary analysis was initiated manually immediately after the first interview was conducted. Notes taken during the interview were read and reread, and the audio file was crosschecked for accuracy. This provided an opportunity to identify some new areas to explore further in the subsequent interviews. It also helped to record some tentative coding schemes (Braun \& Clarke, 2006). Following this, the first interview was transcribed. As the audiotape was being transcribed, the initial extracts were manually categorised into broad themes and subthemes. This process was repeated for the next six interviews. In order to assess the initial thoughts and ideas about coding, both supervisors read and commented on the interviews and the preliminary analysis. These processes turned out to be very useful because they assisted in obtaining an early grasp of the data (Morse, 2012) and some of these subthemes, grouped manually, became the parent nodes, while others were condensed (Saldaña, 2012) into different child nodes when the transcripts were imported into NVivo 10 for further analysis.

When all 31 interviews had been transcribed, the transcripts were read several times and crosschecked and reconciled with the audio recordings before importing them into the NVivo software. Following this, a number of queries were conducted, the first of which was a word frequency query to gain insight into the words most frequently used by the participants and how this could help in understanding the patterns within the whole data set. It also helped with further coding the data (Seale \& Rivas, 2012) because by clicking and 
opening each referenced source the analyst was able to highlight, and drag and drop the extract to the appropriate nodes.

At the end of this process, each transcript was reread and data that had not been coded through the first process were coded. When the coding was completed, the nodes were read thoroughly to identify incompatible quotes. Through these means, such quotes were condensed or expanded into the existing child nodes or new nodes were created before running matrix coding queries. At the end of the matrix queries, the nodes were exported to a word document and read several times. Here, some comparisons with the few tentative themes that had been generated manually were made before recording the patterns of meaning from the key themes that had been identified. These key themes are presented in the ensuing section.

\section{Results}

\section{Overview}

The participants were asked to share their general knowledge about alcohol marketing in the city where the university is located, and to be specific about their experience on this campus. Both male and female participants discussed the use of sales promotion strategies in the city and also on the campus, but they placed much emphasis on their awareness of electronic and outdoor alcohol advertisements, which they see on campus and around students' off-campus leisure sites. They also highlighted their perceptions of the potential effects of these advertisements on their drinking. 


\section{Television Advertisements and Brand Awareness}

When participants were asked to discuss where they had seen alcohol advertising, all of them indicated that they view alcohol advertisements regularly on both terrestrial and satellite television channels. For example, all of the male participants stated that alcohol is regularly advertised during live football games:

Diogor: I see alcohol adverts mostly on TV. In a day, I normally see alcohol adverts like two times. I see some of the drinks when watching sports like football. Normally every week, they play football EPL [English Premier League], and we see adverts during live games. During the halftime break..., they'll bring in alcohol adverts, maybe two to three times...

Boniface: Actually, we see alcohol adverts most times on TV... When we go to watch football on SuperSport [a satellite television channel], we see adverts.

Other male participants emphasised that they also see alcohol advertisements during football games and their accounts highlighted how they were able to 'identify' the particular brands they often see during live games:

Jacob: ...I see adverts three to four times a week... There is no day that I go to watch football [in a viewing centre] that I don't watch any of these alcohol adverts like Guinness [stout], 'Gulder' and 'Star' beers adverts. [They show adverts] before 


\section{the football match starts, during halftime and after the football game. And at other times, the advert keeps moving [on the screen] as long as the football game is on.}

In Nigeria, the 'English Premier League' and other European football leagues are popular among football fans. Again, public commercial "football viewing centres" are popular (Adetunji, 2013). These viewing centres are managed by entrepreneurs, who provide satellite dishes and internet facilities for those who are unable to afford them privately to follow live football games. Although these venues are 'public', women hardly use them because of the informal social structure which not only distinguishes between men's and women's spaces, but also discriminates against women who occupy men's space (Dumbili, 2015c). Many viewers, especially young males often coalesce in these venues during live games due to relatively cheap entrance fees and the growing 'social viewing' in Nigeria. Because many of these viewing centres double as bars/restaurants (Dumbili, 2015a), viewers can purchase and consume alcohol while watching football games. Many of the male participants revealed that they watch football games in different viewing centres around the campus.

A key reason men stated that they watch football games in such venues was that viewing centres unite team supporters, who often consume specific brands while watching live games (i.e., consuming a brand often shows the friendship group to which one belongs and the particular team he supports). For example, it was found that drinking 'Heineken beer' is associated with the possession of a higher economic capital, in that it is believed to be imported and expensive. Therefore, buying many bottles for one's friends or being able to hold one's drink confers status on men in these public leisure sites. Thus, as part of their 'marketing mix', 'Nigerian Breweries' and 'Guinness Nigeria' appear to be drawing on these 
factors through the ownership of viewing centres where they advertise and promote their brands:

Chike: ...There are some specific bars that won't allow you to come in and watch a match unless you buy that brand like Heineken. I once went to a bar they call "Heineken Bar".... They have this public viewing centre where you can view matches, but to have the privilege of staying there, you must buy Heineken.... Personally, I don't drink Heineken, but for the fact that I really wanted to see that match, I bought Heineken... Guinness does the same kind of thing too. It's about football, which they know that a lot of males support. So they tend to bring customers to themselves.

These participants' accounts also highlighted some nuances with regard to the association between football and alcohol in Nigeria:

Fred: ...When you are watching a football game, you also see adverts by Guinness. Football is associated with Guinness because every [English] Premier League game you watch, after the first half, you must see Guinness adverts up to four times before the second half starts. Besides, Guinness even has what they call a ‘Guinness Soccer Manager’.

Interviewer: Do you mean in Nigeria or elsewhere?

Fred: Yes in Nigeria; it is an online thing where you choose a team and become a coach. You will be coaching the team online, and they will be fixing matches for you... Certainly, everyone that watches football knows about it. It is very interesting; if you love football, you will want to participate in it. 
Many of the male participants also recalled another way in which alcohol is associated with football because football fans often consume alcohol for two reasons: to cheer themselves up when the team they support is losing in a game, and to celebrate victories when they win in public viewing centres. It is notable that only two female participants indicated that they had seen alcohol advertisements during football games.

\section{Advertisements embody News and Movies}

When participants were asked to recall whether they see alcohol advertisements in any other television programmes, the women indicated that they see advertisements during the evening news, especially on local television channels because alcohol companies sponsor news sections:

Chisalum: I see adverts on TV, especially during the news because I can remember on 'STV' [a popular local television station], 'Star beer' sponsors entertainment news. So during the news, before the newscaster says it is time for 'entertainment news', there will be a Star [beer] advert... After the entertainment news, they will tell you: 'this entertainment news was brought to you by 'Star, sharing happiness', and they will do an advertisement for Star [beer]...

Some of the male participants had also seen alcohol advertised during the evening news. For example:

Favour: ...I have noticed that most times... adverts always come up so much in the evenings, especially on television. When you are listening to late night news, 
they'll pause for a break to air adverts of this brand or that brand. Also, one of the brands now uses "1759" as its marketing strategy. 1759 is roughly around 5.59PM, and that's the time that is very okay to go and take alcoholic drinks.

The female participant shared their experiences of how they see alcohol advertisements while watching movies and other television programmes:

Pretty: During night-time movies most of the time on local TV stations... they just do this quick advertisement. On DSTV [satellite television], most often you see alcohol advertisements there.

Chichi: ...I've watched some alcohol adverts on TV like "Guinness Stout" adverts, Heineken [beer]; this new one called 'Hero' [beer] and 'Legend' [stout]... We have more beer brands here than spirits, so they concentrate on beer adverts. Like maybe they are showing a 30-minute programme, at least, they will show adverts like three times before the programme ends. Sometimes, they spend more minutes on adverts than the main programme itself...

One of the key convergences in the data is that both male and female participants demonstrated a high level awareness of the brands whose advertisements they see often. Interestingly, participants not only showed that they were aware of the brands, but their accounts also revealed their perceptions of the reason behind alcohol advertisements on television. For example, one stated that 'Guinness Nigeria' make advertisements to create awareness of the quality of their product. A similar view was shared by many others: 
Chimanda: ...When you are watching cable TV, you'll see so many adverts about alcohol. 'Star beer' and other brands come with their adverts to show you how good each drink is and to sell their stuff to you.

Together, these accounts reveal how alcohol is advertised on the terrestrial and satellite television channels that these students watch, and their awareness of these advertisements.

\section{Posters and Billboards bring alcoholic brands closer to students}

The data also revealed that participants had sophisticated levels of awareness of the use of posters, billboards, the painted/branded fences of bars, and other outdoor advertising materials on campus and around students' off-campus residential and leisure spaces. Unlike their awareness of alcohol advertisements on television, which was gendered, their accounts indicated that both male and female participants saw similar outdoor advertisements frequently. For example:

Levin: I think very often around campus [you see adverts]. Even inside the school, in most of the restaurants, you'll see posters... I think the most popular means that they use is poster adverts in the places where they sell drinks. You'll see their banners too; they paint them with their colour, like 'Star beer' is blue....

When the female participants were asked to share their accounts of outdoor alcohol advertising, they 'identified' that marketers employ a broad range of channels. For example, the popularity of point-of-sale advertisements on the campus was highlighted: 
Chisalum: I see adverts on campus; in [name of students' eatery] which students normally use at their leisure or when they feel hungry, you'll see posters of Gulder and Star [beers]; they will even tell you the price. It's rampant...; adverts are very frequent...

While most of the Nigerian universities are non-residential, those with residential status do not provide enough accommodation for their students. Thus, the majority of the students live in private hostels that are usually built around the universities by entrepreneurs. Relatedly, hotels, bars, nightclubs and other leisure sites are strategically located near higher institutions in Nigeria, and this university is not an exception. Many of the participants who reside in the off-campus accommodation noted that while they see alcohol advertisements when they come onto the campus, they are also aware of advertisements around their off-campus residential and leisure sites:

Chichi: ...There are lots of hotels and bars here... and immediately you step into each hotel, you must surely see something like a picture [poster] or a wallpaper of one alcohol brand or another because they are trying to advertise their drinks...

Chioma: I see adverts on billboards here... adverts are everywhere, especially in shops. There is a bridge at [name of a popular off-campus residential site], and there is one alcohol billboard that is there... Adverts are popular because there are different brands here. So if this brand does their advert, another brand will do theirs... 
While the use of posters is common inside the campus, marketers employ billboards and posters outside the university premises:

Fred: ...Usually, adverts inside school may be in small leaflets, but there are large leaflets outside [the school premises]. They use billboards, and at night they have filament bulbs inside the signboard, and when you are passing, you'll be seeing it.

The participants' accounts highlighted their perceptions of the reasons why posters and billboards are used to advertise alcohol around students' environments. Indeed, a substantial number of them indicated that billboards or posters bring the advertisements for a brand closer to the students:

Boniface: The use of posters is the normal thing. You can't have your bar without having posters, especially posters of 'Star beer', 'Guinness Stout' and 'Hero beer.' So you often see posters scattered around bars just to create awareness... Posters are the quickest way to reach students...

Larry: Within this vicinity..., you'll see where 'Star' [beer] will paste their poster, making it looks appetizing or you might see where maybe Gulder [beer] will do their own- with an inscription that reads: “Gulder makes you be a man"... The use of billboards or posters is closer to the student as they must pass by when they are walking around; so you will be seeing it almost every day.

Many participants perceived the density of bars and other leisure spaces (that provide ready-made sites for advertisers) as one of the major reasons for the growing outdoor advertising: 
Chikere: ...'Beer parlours' [bars] litter the streets... so once you go out of the school, the sign[post] for alcoholic drinks and the adverts for beer are the things you will see.

These accounts shed light on the students' perception of the widespread outdoor alcohol advertisements on and around this campus, and showed that both male and female students were highly aware of them, in that their recall of brand names was high.

\section{'New brands', 'Taste' and Advertisements Influence Drinking}

The findings also point to the ways in which awareness of advertisements is perceived to influence the participants' alcohol consumption. While none of the females indicated that alcohol advertisements affected their drinking, some of the male participants noted that they were 'enticed' by alcohol advertisements, and thus they decided to try a new brand. For example, one of them stated that he has recently started to consume 'Hero beer' instead of 'Star beer' he used to drink. Other participants shared similar views:

Larry: I was tempted once by an advert for a creamy alcoholic drink. Because it was creamy and looked very attractive, I wanted to have the drink...

Kelly: Adverts connote a lot... like when 'Hero' [beer] came out, people didn't really know about Hero at all, but now most people have started drinking it. It was 
through television adverts that I saw it, so I just said, 'let me go and taste it and know how it tastes'. I bought and tasted it; the taste was okay for me...

Male participants also revealed the way in which men employed the act of 'being the first person to taste a new beer' among friendship groups to gain social capital:

Boniface: I think advert influences students because most people want to try out a new drink... For example, most guys will want to try new drinks not only because they want to know how it tastes, but also because they want to tell their friends that 'I tasted this drink [before you], and it tastes like this or like that'. Last week I actually drank a new milky stout called 'Castle' because I saw the poster. I had seen the poster..., and I was telling myself that I am going to try this drink.

Our analysis highlighted that the possession of this 'knowledge capital' (i.e., being aware of a new product due to its advertisements) confers a higher status on the possessor, but it may also increase the chances of being influenced by alcohol advertisements (further research is needed to support this claim). Although men revealed that they had their preferred brands, our data showed that tasting a new product (and consequently introducing it to one's friendship network) performed an important role among men.

While alcohol advertisements were perceived to influence some of the men to try new products, they encouraged others to change their originally preferred brands to new ones on a permanent basis:

Buchi: ...Before it was Heineken [beer] that I was drinking, but now what made me like 'Harp' [beer] is one particular advert on the TV that Harp did. I just fell in love 
with that advert, and I just said, 'let me try this Harp thing'. I tried it, and I was okay with it.

Interviewer: How can you describe this advert that made you abandon Heineken?

Buchi: ...The advert was a guy... who went to drink with his friends; so the guy wanted to take the bottle of 'Harp' [beer] from the barman... There was a girl too who wanted to take the [same bottle of] 'Harp' from the bartender, and the bartender told them that there was just one remaining [bottle]... So the guy that wanted to take the bottle of Harp said he had an idea. And the idea was for them to do a dancing competition, and the winner would take the bottle of Harp. So... he danced very well. So it was the turn of the girl, and she danced well too and let me say they drew. He didn't know that the bartender was just playing with them. So after they had danced, the bartender opened another freezer and showed them where many bottles of Harp [beer] were stored. So I just loved that advert.

Together, these accounts reveal the relationships between awareness of electronic and outdoor alcohol advertisements and alcohol consumption among youths. The male participants highlighted the connection between their awareness of new brands and exposure to advertisements. Therefore, they either wanted to taste these new products or had tasted them, which in turn resulted in a change of brands. 


\section{Discussion}

The data presented above shed light on the ways in which Nigerian students were highly aware of the use of electronic and print media alcohol advertisements on and around this campus, including the ways in which this awareness appears to influence their drinking behaviours. In this way, the study makes an important contribution to the sparse literature on how alcohol advertising influences alcohol use in Nigeria. The results show that transnational alcohol corporations and marketers in Nigeria employ both terrestrial and satellite television channels to advertise different brands. As with Gordon et al. (2011) and Jones and Magee (2011), who found that young people's exposure to television alcohol advertisements and their awareness of them were high, both the male and female participants interviewed for this study demonstrated a significant level of awareness of television alcohol advertisements, to the extent that some of them not only recalled brand names but gave vivid descriptions of the advertisements they had seen on television.

An insightful part of the findings is the way in which participants' awareness of, and exposure to advertisements on the television appeared to be gendered. While the male participants saw alcohol advertisements during football games, the females recalled more alcohol advertising during movies and news telecasts. Dumbili (2015a) found that the preference for movie genres and other television programmes among young men and women in Nigeria is gendered. While men prefer action movies (that have little or no alcohol portrayals) and sporting activities, especially football games, women consume foreign epic/drama movies and Nigerian-made films (that have a lot of alcohol portrayals (Aina \& Olorunshola, 2007; Dumbili, 2015a)). 
Because alcohol advertising embodies sports (Babor et al., 2010), in that alcohol industries directly or indirectly sponsor different sports and use the medium to advertise and promote their brands (Graham \& Adams, 2014), Nigerian men who watch football games may be highly aware of, or exposed to high rates of alcohol advertisements and product placement of alcohol brands during live games, and this may affect their immediate or future drinking for the following reasons. First, while exposure to alcohol advertisements influences the development of positive attitudes to starting drinking among youths who have never used alcohol (Morgenstern et al., 2011), it also facilitates alcohol initiation (Anderson et al., 2009), regular and heavy drinking (Jones \& Magee, 2011) and other hazardous drinking styles that exacerbate alcohol-related harms (Grenard, Dent, \& Stacy, 2013). Second, due to the fact that the public 'viewing centres' (where men regularly go to watch games) serve alcohol, and the fact that the men reported the nexus between football and alcohol (i.e., people drink to celebrate victories, to copy when their teams lose and to display their economic capital), seeing advertisements repeatedly may produce what media scholars called a 'double-dose' or "resonance effect" on the viewers (Potter, 2014 p., 1019).

Additionally, viewing alcohol portrayals on television in an environment where alcohol is readily available has been found to influence young people's immediate drinking (Dal Cin et al., 2009). Although not many of the women saw alcohol advertisements during sports, they nonetheless saw advertisements and other portrayals of alcohol while watching movies and other television programmes, and they demonstrated a high awareness of the brands that are advertised.

Additional findings show that outdoor alcohol advertisements are popular on campus and around students' off-campus residential and leisure sites, and both male and 
female participants reported seeing them regularly. One serious concern about this result is that the numerous alcohol outlets on these sites provide spaces for posters, billboards, branded fences and other point-of-sale advertising materials. Studies elsewhere show that while the awareness of, and exposure to outdoor advertisements in residential areas engender problem drinking (Kwate \& Meyer, 2009), alcohol outlet density exacerbates alcohol use among youths (Huckle, Huakau, Sweetsur, Huisman, \& Casswell, 2008). Again, outdoor advertisements placed near schools increased the intention to consume alcohol amongst students (Anderson et al., 2009). Although, in principle, APCON's code of practice prohibits the placement of outdoor advertisements close to schools (de Bruijin et al., 2014), the findings of this study suggest that marketers do not obey this regulation. While regulation restricting the locations where alcohol advertisements are sited in Western countries such as the UK and Germany are enforced (Patil et al., 2014), this does not appear to be the case in Nigeria.

Most importantly, the data reveal that seeing alcohol advertisements regularly, especially on television, is perceived to have influenced some of the participants to consume alcohol. While some of the men had tried new products, others were influenced to change their brands (Roberts et al., 2016). It was also found that the culture of tasting new brands connects with advertising to engender men's consumption of alcohol. Because new products are regularly advertised, and men were aware of their advertisements, they are likely to consume new brands (even if this is on a temporary basis). This result supports previous studies (Anderson et al., 2009; Austin et al., 2006; Smith \& Foxcroft, 2009) that found that alcohol advertisements influence young people's drinking, but in this study only 
males were affected, despite the fact that their female counterparts were also aware of the alcohol advertisements.

Although the effects of alcohol advertisements were found to be gendered in Jones and Magee's (2011) study, both males and females reported consuming alcohol in that study due to the influence of advertisements. One possible explanation for the gendered effects in the current study is that women reported a high awareness of the advertisements for alcoholic beverages that are 'categorised' as 'men's alcohol' in Nigeria. Nigeria is a patriarchal society, where alcohol consumption is not only gendered, but alcoholic beverages are also gendered too (Dumbili, 2015b). While men drink beer, rum and gin, women drink sweetened/flavoured beverages such as wine (Dumbili, 2015b). This informal social structure may have affected the women's response to the advertisements for beer and stout, especially because such advertisements may have been dominated by masculine themes.

\section{Conclusion}

The study has some limitations, one of which is that not many female participants were included due to the recruitment issues discussed above. Future studies might consider employing female researchers for data collection. Another limitation is that the study relied on the accounts of the participants without monitoring alcohol advertising on the television (although outdoor advertising was partly monitored in the pilot phase). Additionally, the data were collected from people who share the same ethnoreligious beliefs. 
Nigeria does not have written national alcohol control policies (Ferreira-Borges et al., 2015), and it appears that the existing APCON code is not effectively implemented. Based on the accounts of the participants, which showed that alcohol is advertised during the day (on satellite television channels), especially during football games, this study recommends that the monitoring of advertisements and other marketing activities should be prioritised in Nigeria. The importance of effective monitoring is underpinned by the fact that alcohol companies in Nigeria mainly rely on self-regulation, which is often ineffective (Zwarun \& Farrar, 2005). It might also be beneficial for an independent monitoring team to be set up to assist in checking the marketing activities of transnational alcohol industries. This is especially because:

"where alcohol industry self-regulation is the primary protection against youth exposure to alcohol advertising, independent, systematic monitoring of youth exposure can promote public awareness of and greater accountability in the industry's practices" (Jernigan, Ostroff, \& Ross, 2005 p., 312).

Research shows that regulating alcohol advertising with strict regulatory measures reduces hazardous consumption and alcohol-related problems (Bosque-Prous et al., 2014). Policymakers in Nigeria might also consider replacing self-regulation with effective and evidence-based regulatory measures of alcohol advertisements. This would "reduce exposure to the very large risk posed by alcohol both to the students and the general population" (Siegfried et al., 2014 p., 7).

Although none of the female participants reported being influenced by advertisements, they are potential targets for marketers, and this should not be neglected in the regulatory process. This is significant because alcohol industries in Nigeria have 
recently introduced many female-friendly alcoholic beverages, and are emphasising 'drinking and women's independence' through the media (Obot, 2013). In conclusion, the findings of this study have highlighted the extent to which Nigerian youths are aware of alcohol advertisements, and their perceptions of how they influence drinking behaviours. It is hoped that these results will encourage discussions around the enforcement of existing regulations in order to promote public health in Nigeria.

\section{References}

Abayomi, O., Onifade, P. O., Adelufosi, A. O., \& Akinhanmi, A. O. (2013). Psychosocial correlates of hazardous alcohol use among undergraduates in southwestern Nigeria. General Hospital Psychiatry, 35(3), 320-324.

Ademigbuji, A. (2013). Fireworks as Guinness and APCON differ on banned extra-stout ad. Retrieved from http://nationalmirroronline.net/new/fireworks-as-guinness-apcondiffer-on-banned-extra-stout-ad/

Adetunji, A. (2013). A discursive construction of teasing in football fandom: The context of the south-western Nigerian viewing centre. Discourse \& Society, 24(2), 147-162.

Adewuya, A. O., Ola, B. A., \& Aloba, O. O. (2006). Gender differences in the relationship between alcohol use and anxiety symptoms among Nigerian college students. Drug and Alcohol Dependence, 85(3), 255-257.

Aina, O. F., \& Olorunshola, D. A. (2007). Alcohol and substance use portrayals in Nigerian video tapes: An analysis of 479 films and implications for public drug education. International Quarterly of Community Health Education, 28(1), 63-71. 
Akpata, E. S., Adeniyi, A., Enwonwu, C., Adeleke, O., \& Otoh, E. (2014). Association between alcohol consumption and periodontal disease among older Nigerians in plateau state: A preliminary study. Gerodontology, Early View, DOI: 10.1111/ger.12173.

Akpotaire, U. (2016). Nigeria's advertising laws, regulations and Guidelines: The Simple "don'ts". Retrieved from http://nlipw.com/nigerias-advertising-laws-the-simple-donts/

Anderson, P., Chisholm, D., \& Fuhr, D. C. (2009). Effectiveness and cost-effectiveness of policies and programmes to reduce the harm caused by alcohol. The Lancet, 373(9682), 2234-2246.

Anderson, P., de Bruijn, A., Angus, K., Gordon, R., \& Hastings, G. (2009). Impact of alcohol advertising and media exposure on adolescent alcohol use: A systematic review of longitudinal studies. Alcohol and Alcoholism, 44(3), 229-243.

APCON. (2014). Advertising practitioners council of Nigeria. Retrieved from http://www.apcon.gov.ng/

Atkinson, A. M., Bellis, M., \& Sumnall, H. (2013). Young peoples' perspective on the portrayal of alcohol and drinking on television: Findings of a focus group study. Addiction Research \& Theory, 21(2), 91-99.

Austin, E. W., Chen, M. J., \& Grube, J. W. (2006). How does alcohol advertising influence underage drinking? The role of desirability, identification and skepticism. Journal of Adolescent Health, 38(4), 376-384.

Babor, T., Caetano, R., Casswell, S., Edwards, G., Giesbrecht, N., Graham, K., ... Rossow, I. (2010). Alcohol: No ordinary commodity: Research and public policy (Second ed.). New York: Oxford University Press. 
Bosque-Prous, M., Espelt, A., Guitart, A. M., Bartroli, M., Villalbí, J. R., \& Brugal, M. T. (2014). Association between stricter alcohol advertising regulations and lower hazardous drinking across European countries. Addiction, 109(10), 1634-1643.

Braun, V., \& Clarke, V. (2006). Using thematic analysis in psychology. Qualitative Research in Psychology, 3(2), 77-101.

Carr, S., O'Brien, K. S., Ferris, J., Room, R., Livingston, M., Vandenberg, B., ... Lynott, D. (2015). Child and adolescent exposure to alcohol advertising in Australia's major televised sports. Drug and Alcohol Review, Early View, DOI: 10.1111/dar.12326.

Chen, M., Grube, J. W., Bersamin, M., Waiters, E., \& Keefe, D. B. (2005). Alcohol advertising: What makes it attractive to youth? Journal of Health Communication, 10(6), 553-565.

Chikere, E. I. C., \& Mayowa, M. O. (2011). Prevalence and perceived health effect of alcohol use among male undergraduate students in Owerri, south-east Nigeria: A descriptive cross-sectional study. BMC Public Health, 11(1), 118.

Dal Cin, S., Worth, K. A., Gerrard, M., Gibbons, F. X., Stoolmiller, M., Wills, T. A., \& Sargent, J. D. (2009). Watching and drinking: Expectancies, prototypes, and friends' alcohol use mediate the effect of exposure to alcohol use in movies on adolescent drinking. Health Psychology, 28(4), 473.

Davoren, M. P., Cronin, M., Perry, I. J., Demant, J., Shiely, F., \& O'Connor, K. (2016). A typology of alcohol consumption among young people - A narrative synthesis. Addiction Research \& Theory, 24(4), 261-273.

De Bruijin, A., Ferreira-Borges, C., Engels, R., \& Bhavsar, M. (2014). Monitoring outdoor alcohol advertising in developing countries: Findings of a pilot study in five African countries. African Journal of Drug and Alcohol Studies, 13(1), 13-29. 
Dumbili, E. W. (2014). Can brewer-sponsored "drink responsibly" warning message be effective without alcohol policies in Nigeria? Drugs: Education, Prevention and Policy, 21(6), 434-439.

Dumbili, E. W. (2015a). Media, alcohol consumption and young people in an eastern Nigerian university: A qualitative study. (Unpublished PhD). Brunel University London, United Kingdom.

Dumbili, E. W. (2015b). 'What a man can do, a woman can do better': Gendered alcohol consumption and (de) construction of social identity among young Nigerians. BMC Public Health, 15(1), 167. DOI 10.1186/s12889-015-1499-6.

Dumbili,

E.

W.

(2015c).

"She encourages people to drink": A qualitative study of the use of females to promote beer in Nigerian institutions of learning - Drugs: Education, Prevention and Policy, Online First, DOI: 10.3109/09687637.2015.1119246.

Dumbili, E. W. (2016a). Gendered sexual uses of alcohol and associated risks: A qualitative study of Nigerian university students. BMC Public Health, 16(1), 474. DOI 10.1186/s12889-016-3163-1.

Dumbili, E. W. (2016b). Intoxicating entertainment? The influence of "Star music trek" on the drinking practices of Nigerian students. Contemporary Drug Problems, 43(1), 62-78. Ferreira-Borges, C., Esser, M. B., Dias, S., Babor, T., \& Parry, C. D. (2015). Alcohol control policies in 46 African countries: Opportunities for improvement. Alcohol and Alcoholism, 50(4), 470-476. 
Ferreira-Borges, C., Rehm, J., Dias, S., Babor, T., \& Parry, C. D. (2016). The impact of alcohol consumption on African people in 2012: An analysis of burden of disease. Tropical Medicine \& International Health, 21(1), 52-60.

Gordon, R., Moodie, C., Eadie, D., \& Hastings, G. (2010). Critical social marketing-the impact of alcohol marketing on youth drinking: Qualitative findings. International Journal of Non-profit and Voluntary Sector Marketing, 15(3), 265-275.

Gordon, R., Harris, F., Marie Mackintosh, A., \& Moodie, C. (2011). Assessing the cumulative impact of alcohol marketing on young people's drinking: Cross-sectional data findings. Addiction Research \& Theory, 19(1), 66-75.

Graham, A., \& Adams, J. (2014). Alcohol marketing in televised English professional football: A frequency analysis. Alcohol and Alcoholism, 49(3), 343-348.

Grenard, J. L., Dent, C. W., \& Stacy, A. W. (2013). Exposure to alcohol advertisements and teenage alcohol-related problems. Pediatrics, 131(2), e369-e379.

Huckle, T., Huakau, J., Sweetsur, P., Huisman, O., \& Casswell, S. (2008). Density of alcohol outlets and teenage drinking: Living in an alcogenic environment is associated with higher consumption in a metropolitan setting. Addiction, 103(10), 1614-1621.

Igwe, W. C., \& Ojinnaka, N. C. (2010). Mental health of adolescents who abuse psychoactive substances in Enugu, Nigeria-A cross-sectional study. Italian Journal of Pediatrics, 36(1), 1-5.

Jernigan, D. H. (2012). Global alcohol producers, science, and policy: The case of the International Center for Alcohol Policies. American Journal of Public Health, 102(1), 8089.

Jernigan, D. H., Ostroff, J., \& Ross, C. (2005). Alcohol advertising and youth: A measured approach. Journal of Public Health Policy, 26(3), 312-325. 
Jones, S. C., Barrie, L., \& Berry, N. (2012). Why (not) alcohol energy drinks? A qualitative study with Australian university students. Drug and Alcohol Review, 31(3), 281-287.

Jones, S. C., \& Magee, C. A. (2011). Exposure to alcohol advertising and alcohol consumption among Australian adolescents. Alcohol and Alcoholism, 46(5), 630-637.

Kwate, N. O. A., \& Meyer, I. H. (2009). Association between residential exposure to outdoor alcohol advertising and problem drinking among African American women in New York City. American Journal of Public Health, 99(2), 228-230.

Kypri, K., Paschall, M. J., Langley, J., Baxter, J., Cashell-Smith, M., \& Bourdeau, B. (2009). Drinking and Alcohol-Related harm among New Zealand university students: Findings from a national Web-Based survey. Alcoholism: Clinical and Experimental Research, 33(2), 307-314.

Lim, S. S., Vos, T., Flaxman, A. D., Danaei, G., Shibuya, K., Adair-Rohani, H., ... Andrews, K. G. (2013). A comparative risk assessment of burden of disease and injury attributable to 67 risk factors and risk factor clusters in 21 regions, 1990-2010: A systematic analysis for the global burden of disease study 2010. The Lancet, 380(9859), 2224-2260.

Martino, S. C., Kovalchik, S. A., Collins, R. L., Becker, K. M., Shadel, W. G., \& D'Amico, E. J. (2016). Ecological momentary assessment of the association between exposure to alcohol advertising and early adolescents' beliefs about alcohol. Journal of Adolescent Health, 58(1), 85-91.

Morgenstern, M., Isensee, B., Sargent, J. D., \& Hanewinkel, R. (2011). Exposure to alcohol advertising and teen drinking. Preventive Medicine, 52(2), 146-151.

Morse, J. M. (2012). The implications of interview type and structure in mixed-method designs. In J. F. Gubrium, J. A. Holstein, A. Marvasti \& K. D. McKinney (Eds.). The SAGE Handbook of Interview Research: the complexity of the craft. Los Angeles: SAGE Pub. 
Obot, I., \& Ibanga, A. (2002). Selling booze: Alcohol marketing in Nigeria. The Globe, 2, 6-10.

Obot, I. S. (2007). Nigeria: Alcohol and society today. Addiction, 102(4), 519-522.

Obot, I. (2013). Alcohol marketing in Africa: Not an ordinary business. African Journal of Drug and Alcohol Studies, 12(1), 63-73.

Patil, S., Winpenny, E. M., Elliott, M. N., Rohr, C., \& Nolte, E. (2014). Youth exposure to alcohol advertising on television in the UK, the Netherlands and Germany. European Journal of Public Health, 24(4), 561-565.

Pettigrew, S., Biagioni, N., Jones, S. C., Daube, M., Kirby, G., Stafford, J., \& Chikritzhs, T. (2015). Sales promotion strategies and youth drinking in Australia. Social Science \& Medicine, 141, 115-122.

Pettigrew, S., Jongenelis, M., Pratt, I. S., Liang, W., Slevin, T., Chikritzhs, T., \& Glance, D. (2016). Australian drinkers' perceptions of alcohol-related risk by consumption status. Addiction Research \& Theory, Online First, DOI:10.1080/16066359.2016.1175557.

Potter, W. J. (2014). A critical analysis of cultivation theory. Journal of Communication, 64(6), 1015-1036.

Qian, F., Ogundiran, T., Hou, N., Ndom, P., Gakwaya, A., Jombwe, J., ... Ojengbede, O. (2014). Alcohol consumption and breast cancer risk among women in three sub-Saharan African countries. PloS One, 9(9), e106908.

Rehm, J., Mathers, C., Popova, S., Thavorncharoensap, M., Teerawattananon, Y., \& Patra, J. (2009). Global burden of disease and injury and economic cost attributable to alcohol use and alcohol-use disorders. The Lancet, 373(9682), 2223-2233.

Roberts, S. P., Siegel, M. B., DeJong, W., Ross, C. S., Naimi, T., Albers, A., ... Jernigan, D. H. (2016). Brands matter: Major findings from the alcohol brand research among underage drinkers (ABRAND) project. Addiction Research \& Theory, 24(1), 32-39. 
Ross, C. S., Bruijn, A., \& Jernigan, D. (2013). Do time restrictions on alcohol advertising reduce youth exposure? Journal of Public Affairs, 13(1), 123-129.

Saffer, H., \& Dave, D. (2006). Alcohol advertising and alcohol consumption by adolescents. Health Economics, 15(6), 617-637.

Saldaña, J. (2012). The coding manual for qualitative researchers. London: Sage Publications Ltd.

Seale, C., \& Rivas, C. (2012). Using software to analyze qualitative interviews. In J. F. Gubrium, J. A. Holstein, A. Marvasti \& K. D. McKinney (Eds.), The SAGE handbook of interview research: The complexity of the craft (second ed., pp. 427-440). Los Angeles: SAGE Pub.

Siegfried, N., Pienaar, D. C., Ataguba, J. E., Volmink, J., Kredo, T., Jere, M., \& Parry, C. D. (2014). Restricting or banning alcohol advertising to reduce alcohol consumption in adults and adolescents. The Cochrane Library,

Silverman, D. (2011). Interpreting qualitative data (4th ed.). London: Sage Publications Limited.

Smith, L. A., \& Foxcroft, D. R. (2009). The effect of alcohol advertising, marketing and portrayal on drinking behaviour in young people: Systematic review of prospective cohort studies. BMC Public Health, 9(1), 51. DOI: 10.1186/1471-2458-9-51.

Stockings, E., Hall, W. D., Lynskey, M., Morley, K. I., Reavley, N., Strang, J., ... Degenhardt, L. (2016). Prevention, early intervention, harm reduction, and treatment of substance use in young people. The Lancet Psychiatry, 3(3), 280-296.

Unger, J. B., Schuster, D., Zogg, J., Dent, C. W., \& Stacy, A. W. (2003). Alcohol advertising exposure and adolescent alcohol use: A comparison of exposure measures. Addiction Research \& Theory, 11(3), 177-193. 
Zwarun, L., \& Farrar, K. M. (2005). Doing what they say, saying what they mean: Selfregulatory compliance and depictions of drinking in alcohol commercials in televised sports. Mass Communication \& Society, 8(4), 347-371. 